\title{
Dishevelled interacts with p65 and acts as a repressor of NF-kB-mediated transcription
}

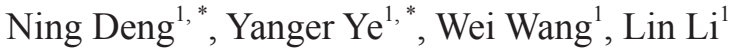 \\ ${ }^{I}$ State Key Laboratory of Molecular Biology, Institute of Biochemistry and Cell Biology, Shanghai Institutes for Biological Sci- \\ ences, Chinese Academy of Sciences, Shanghai 200031, China
}

Dishevelled (Dvl) is a highly conserved protein family that plays an important role in mediating Wnt signaling from membrane to cytoplasm. Recently we reported that Dvl also functions in the nucleus by stabilizing the $\beta$-catenin/TCFs transcriptional complex. Here we describe that Dvl may function as a repressor of NF- $\kappa B$. Our data show that Dvl directly binds to $\mathrm{p} 65$ and their interaction occurs in the nucleus. Dvl expression inhibits p65-mediated or TNF- $\alpha$-stimulated activation of the NF-אB dependent reporter. This action of Dvl, however, is not dependent on Wnt or its downstream effector $\beta$-catenin. Chromatin immunoprecipitation assay shows that recruitment of p65 to the promoters of NF- $\mathrm{BB}$ target genes is significantly enhanced when expression of Dvl is knocked down. Consistently, the expression level of a subset of $\mathrm{NF}-\kappa \mathrm{B}$ target genes is also increased after knock-down of Dvl. Moreover, our data suggest that Dvl may relieve the anti-apoptotic effect of $\mathrm{NF}-\mathrm{KB}$, thus play a role in promoting apoptosis. Therefore, this work demonstrates a novel function of Dvl in modulating NF-кB-regulated gene transcription.

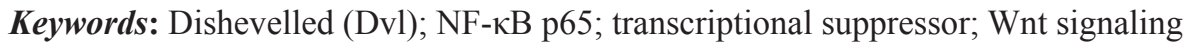

Cell Research (2010) 20:1117-1127. doi:10.1038/cr.2010.108; published online 13 July 2010

\section{Introduction}

The Wnt signaling pathway plays important roles in a wide range of biological processes, such as embryonic induction, generation of cell polarity and cell fate determination [1-5]. Among the components in the canonical Wnt signaling cascade, dishevelled (Dvl) is generally considered as the most upstream cytosolic molecule once Wnt ligands are bound to the receptor. After activation of Dvl, the activity of GSK-3 is inhibited and the scaffold protein of the $\beta$-catenin degradation complex-Axin is consequently destabilized. Eventually, $\beta$-catenin is stabilized and accumulates in the nucleus to activate $\mathrm{TCF} /$ LEF-1 target genes. Recent studies have unraveled that Dvl also functions in the nucleus [6], through stabilizing $\beta$-catenin/TCF interaction by forming a quaternary complex consisting of Dvl, c-Jun, $\beta$-catenin and TCF [7]. In addition to regulating the canonical Wnt signaling,

\footnotetext{
*These two authors contributed equally to this work.

Correspondence: Lin Li

E-mail: 1li@sibs.ac.cn

Received 1 March 2010; revised 13 May 2010; accepted 17 May 2010; published online 13 July 2010
}

Dvl has also been suggested to be an essential transducer in non-canonical Wnt signaling pathways $[8,9]$. It is believed that the ability of Dvl molecule to interpret distinct types of stimuli and transmit them to distinct sets of effectors decides which event(s) would occur in Wntresponsive cells [10].

$\mathrm{NF}-\kappa \mathrm{B}$ is a family of dimeric transcription factors including five members: RelA (also called p65), RelB, cRel, p105/p50 and p100/p52. In many cell types, the predominant NF- $\kappa \mathrm{B}$ species are p65-p50 heterodimers [11]. All members share a highly conserved Rel homology domain that has been known to confer DNA-binding, protein dimerization and nuclear localization properties. In addition, p65, RelB and c-Rel contain a transactivation domain (TAD) at the C-terminus [12]. In resting cells, most NF- $\kappa B$ dimers are found in the cytoplasm in an inactive form through association with a member of IאB inhibitor proteins. Once the cells are stimulated by a specific signal, I $\kappa \mathrm{B}$ is rapidly phosphorylated, ubiquitinated and degraded by the $26 \mathrm{~S}$ proteasome, allowing NF- $\kappa \mathrm{B}$ to translocate to the nucleus to induce the expression of specific genes involved in immune response, inflammation, cell proliferation and oncogenesis [13-15]. Dysregulation of NF- $\mathrm{KB}$ activity is linked to a wide range of 
pathological processes, including chronic inflammation, cancer and abnormal development [16-18]. Thus, the activity of NF- $\kappa \mathrm{B}$ must be strictly modulated.

Three Dvl genes have been identified in mammals and all Dvl proteins contain three highly conserved regions: an amino-terminal DIX domain, a central PDZ domain and a carboxyl-terminal DEP domain [19-22]. The requirement of these domains for distinct signaling pathways varies: the DIX domain is essential for $\beta$-catenin activation, the DEP domain is implicated in the activation of the JNK pathway, while the PDZ domain is required for both [22]. Dvl is known to have about 30 interacting proteins [23]. Among these proteins, there are a number of other signaling molecules besides the components of Wnt signaling, indicating that Dvl may exist in a variety of complexes and may play multiple roles under various conditions. In this study, we demonstrate that Dvl interacts with p65 in the nucleus and inhibits p65-mediated $\mathrm{NF}-\mathrm{\kappa B}$ activation through suppressing the DNA-binding activity of p65, thereby regulates the expression of NF$\kappa \mathrm{B}$ target genes and sensitizes cells to TNF- $\alpha$-induced apoptosis.

\section{Results}

\section{Dvl interacts with RelA/p65}

To identify novel Dvl-interacting proteins, we performed a yeast two-hybrid screening of a mouse embryonic cDNA library in which a truncated form of Dvl-1, Dvl-1-C1, was used as the bait. The p65 subunit of NF$\kappa \mathrm{B}$ was characterized as one of the positive clones (Figure 1A). To confirm the interaction between Dvl and p65, we co-transfected HA-tagged p65 with the three Flag-tagged isoforms of Dvl family, Dvl-1, Dvl-2 and Dvl-3, respectively, into HEK293T cells. At $24 \mathrm{~h}$ post-transfection, whole-cell lysates were utilized in the co-immunoprecipitation experiment using anti-Flag antibody. As shown in Figure 1B, p65 could be co-immunoprecipitated with Flag-Dvls.

We further performed coimmunoprecipitation (coIP) experiments using truncation mutants of Dvl-1 to identify the region involved in the association with p65. It was found that Dvl-1 C-terminal 200 amino acids (designated as Dvl-1-C2) were responsible for the binding to $\mathrm{p} 65$ (Figure 1C). To determine the Dvl-binding region within $\mathrm{p} 65$, we also constructed a series of $\mathrm{p} 65$ deletion mutants. The results showed that the region encompassing residues 169-285 in p65 (designated as p65-M) was required for its specific interaction with Dvl (Figure 1C).

To explore whether Dvl could directly interact with p65, we carried out an in vitro GST pull-down assay using recombinant GST-Dvl-1-C1 and 6His-p65-N3 (amino acids 1-330) proteins expressed in Escherichia coli. As shown in Figure 1D, GST-Dvl-1-C1, but not GST, was able to pull down 6His-p65-N3, demonstrating that Dvl bound to $\mathrm{p} 65$ directly.

\section{Dvl inhibits $T N F-\alpha-i n d u c e d N F-\kappa B$ transcriptional activ- ity}

Since Dvl is well known as one of the critical transducers in the Wnt signaling pathway and p65 is a central component of NF- $\mathrm{kB}$ signaling, we were curious about whether these two pathways cross-talk through the interaction of Dvl and p65. Previously, it has been reported that p65 could specifically suppress the activity of Wnt signaling but affect neither the nuclear translocation of $\beta$-catenin nor the DNA-binding ability of the $\beta$-catenin/ TCF complex, suggesting that p65 modified this signaling pathway after the binding of the $\beta$-catenin/TCF complex with target DNA [24]. Given the fact that Dvl either acts as a transducer upstream of $\beta$-catenin or plays a role in stabilizing the $\beta$-catenin/TCF complex in Wnt signaling [7], we favored the notion that the interaction between Dvl and p65 might not have a role in the p65mediated inhibition of the Wnt pathway. Thus, we ask whether Dvl would participate in the regulation of NF$\kappa \mathrm{B}$ signaling. Initially, we used a $\kappa \mathrm{B}-\mathrm{Luc}$ reporter gene to evaluate the effect of over-expression of Dvl on NF- $\kappa B$ activation. HEK293T cells were transiently transfected with Dvl-1, 2 or 3 and a luciferase reporter construct containing three copies of the NF- $\mathrm{KB}$ binding site. After transfection for $24 \mathrm{~h}$, cells were either left untreated or treated with TNF- $\alpha$ for an additional $8 \mathrm{~h}$ before luciferase assays were performed. Interestingly, we found that over-expression of Dvl resulted in dramatic repression of TNF- $\alpha$-induced NF- $\kappa B$ transcriptional activity (Figure $2 \mathrm{~A}$, left). To further investigate the role of endogenous Dvl in the regulation of NF- $\kappa \mathrm{B}$ activity, we performed loss-of-function experiments using the method of RNAi [7]. As shown in Figure 2A, right, knock-down of endogenous Dvls significantly enhanced TNF- $\alpha$-stimulated reporter gene activity, which is consistent with the overexpression studies and suggests that Dvl is a negative regulator of the NF- $\mathrm{\kappa B}$ signaling pathway.

We also investigated whether induction of NF- $\mathrm{NB}$ dependent target genes was altered by Dvl. Cells transfected with Dvl expression plasmid were treated with TNF- $\alpha$ for various time periods. Total RNA was isolated and used to measure endogenous mRNA levels of IкB- $\alpha$, A20, IP-10 and GADD $45 \beta$ by quantitative real-time PCR. Consistently, the induction of these genes was attenuated when Dvl was over-expressed (Figure 2B). Meanwhile, as shown in Figure 2C, the induction of I $\mathrm{B}-\alpha, \mathrm{A} 20, \mathrm{IP}-10$ and GADD45 $\beta$ was increased when 
A

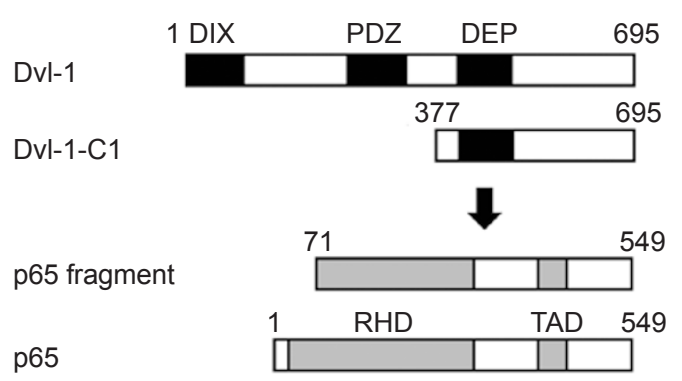

C
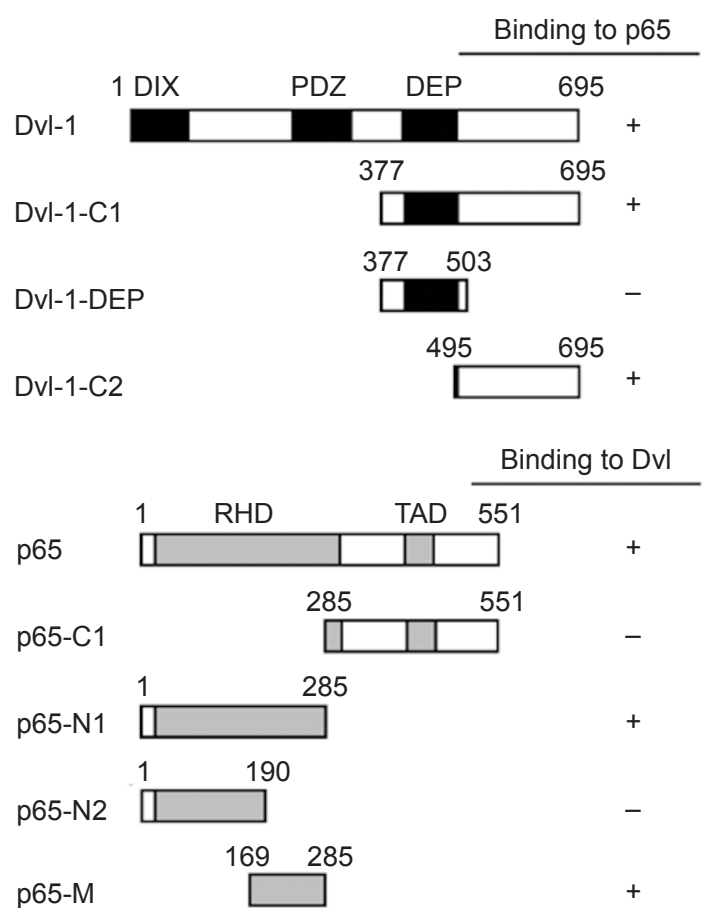

B

$\begin{array}{lllll}\text { HA-p65 } & + & + & + & + \\ \text { Dvl-1-Flag } & - & + & - & - \\ \text { Dvl-2-Flag } & - & - & + & - \\ \text { Dvl-3-Flag } & - & - & - & +\end{array}$
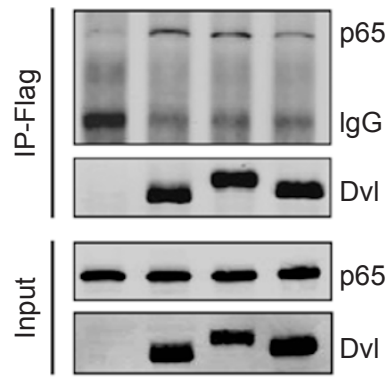

D

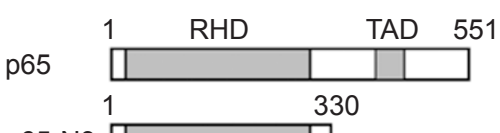

p65-N3 ए- D

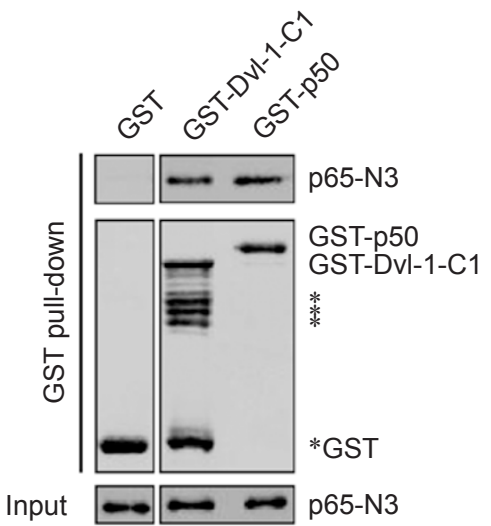

Figure 1 Dvl interacts with p65. (A) Schematic representation of the "bait"-Dvl-1 truncate (Dvl-1-C1) and one "prey"-p65 truncate in a yeast two-hybrid assay. (B) Identification of Dvl as a novel p65-interacting protein. HA-tagged p65 were cotransfected with Flag-tagged Dvl-1-3 separately into HEK293T cells as indicated. After transfection for $24 \mathrm{~h}$, cells were lysed, immunoprecipitated with anti-Flag antibody and analyzed by western blotting. (C) Schematic representation of mapping the binding site on Dvl-1 and p65. The summary of various Dvl-1 constructs binding with p65 and various p65 constructs binding with Dvl-1 in co-IP experiments is tabulated at the right. (D) Dvl directly binds to p65 in vitro. Bacterially expressed GST-Dvl1-C1 fusion protein was purified using glutathione agarose beads and incubated with 6×His-tagged p65 truncate (p65-N3). Associated 6×His-p65-N3 was readily detected by immunoblotting. The asterisk denotes degraded bands of GST-Dvl-1-C1 fusion protein. An equimolar amount of GST was used as a negative control and GST-p50 as a positive control.

expression of Dvl was knocked down using siRNAs. Collectively, our data indicate that Dvl negatively regulates the expression of a series of TNF- $\alpha$-induced genes.

\section{Dvl-mediated inhibition of $N F-\kappa B$ is independent of Wnt signaling or its downstream component $\beta$-catenin}

It was reported that $\beta$-catenin could function as a repressor to inhibit NF- $\kappa$ B activity [25]. Since Dvl is a critical intracellular component of the Wnt signaling pathway, we were then interested in determining whether inhibition of NF- $\kappa \mathrm{B}$ by Dvl was a downstream consequence of Wnt pathway activation. To test this possibility, first, we transfected HEK293T cells with $\kappa B$-Luc reporter and stimulated them with Wnt-3a and TNF- $\alpha$ either separately or together. Luciferase assays showed that Wnt-3a did not inhibit the activation of NF- $\kappa \mathrm{B}$, while the same amount of Wnt-3a could activate transcription of the LEF-1 reporter gene by almost 6 -fold over the con- 
A
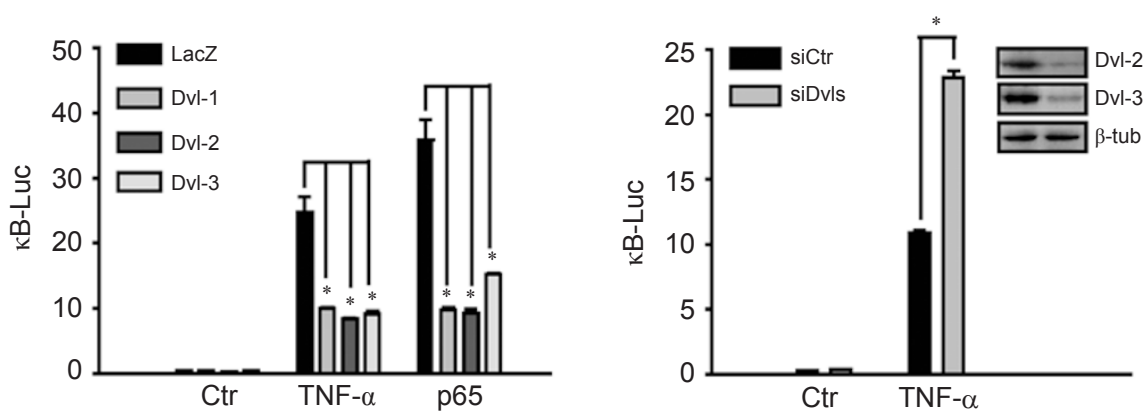

B
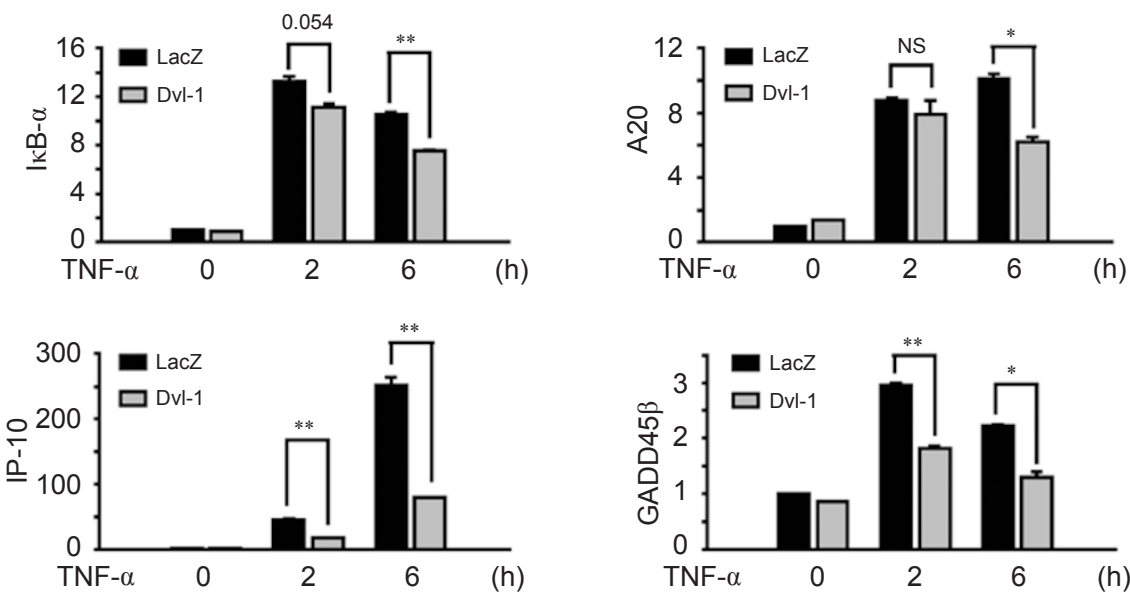

C
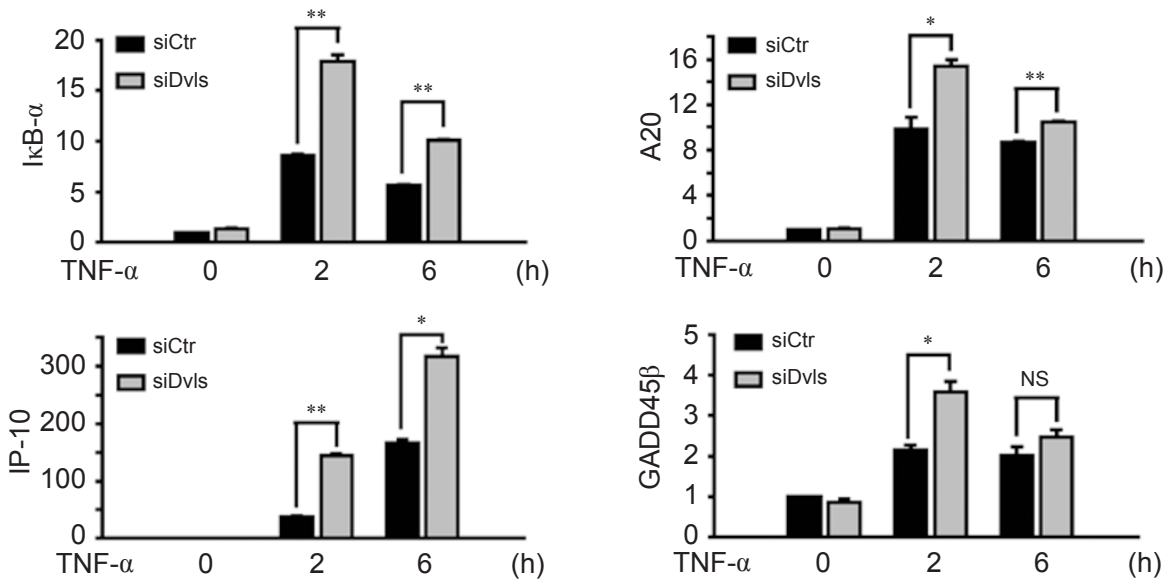

Figure 2 Dvl inhibits TNF- $\alpha$-induced NF-kB activation. (A) Left panel: over-expression of Dvl significantly repressed TNF- $\alpha-$

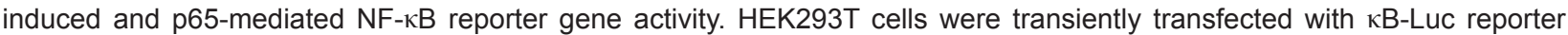
plasmid and the indicated plasmids. After transfection for $24 \mathrm{~h}$, cells were either untreated or treated with $10 \mathrm{ng} / \mathrm{ml}$ TNF- $\alpha$ for $8 \mathrm{~h}$ before luciferase assays were performed. Right panel: SiRNA against Dvl relieved the Dvl-mediated suppression of NF$\kappa B$ activation. Cells were transfected with $\kappa B-L u c$ reporter plasmid plus siDvl-1/3 and siDvl-2. At $48 \mathrm{~h}$ after transfection, cells were either untreated or treated with TNF- $\alpha$. Western analysis of the Dvl-2 and Dvl-3 expression level is shown in the inlet. (B) Over-expression of Dvl repressed expression of NF-kB-regulated genes in response to TNF- $\alpha$. Cells were transfected with Dvl-1 expression plasmid and treated with TNF- $\alpha$ for the indicated times. Endogenous mRNA expressions of IкB- $\alpha$, A20, IP10 and GADD45 $\beta$ were measured by real-time RT-PCR. (C) Knock-down of Dvl enhanced NF-kB-regulated gene expression. Cells were transfected with Dvl siRNA for $48 \mathrm{~h}$ and then treated as in (B). Data are shown as means \pm SD of at least three independent experiments. ${ }^{*} P<0.05$; ${ }^{*} P<0.01$; NS, no statistical significance, using Student's $t$ test. 
trol (Figure 3A). Then we transfected 293T cells with 25 ng of Dvl or different amounts of $\beta$-catenin expression plasmids and tested their effects in two reporter systems: LEF-1 reporter and $\kappa B-L u c$ reporter. The results showed that over-expression of $25 \mathrm{ng}$ of Dvl resulted in an approximately 12 -fold increase in the LEF-1 reporter activity (Figure 3B, top), while inhibiting TNF $\alpha$-induced NF$\kappa \mathrm{B}$ activity to $22 \%$ (Figure $3 \mathrm{~B}$, bottom). Meanwhile, 10 ng of $\beta$-catenin was able to activate the LEF-1 reporter gene by almost 3- to 4-fold over Dvl (Figure 3B, top), but it could only inhibit NF- $\mathrm{kB}$ to $78 \%$ (Figure $3 \mathrm{~B}$, bottom). In addition, we also expressed Axin, a molecule that would block the activation of $\beta$-catenin, along with Dvl. Axin clearly inhibited the activation of LEF-1 reporter by Dvl (Figure 3C, left), but it did not relieve Dvlmediated suppression of NF- $\mathrm{BB}$ activity (Figure $3 \mathrm{C}$, right). These results suggest that the inhibition of NF- $\kappa B$ by Dvl is neither dependent on Wnt signaling nor mediated through its downstream component $\beta$-catenin.

Dvl interacts with p65 in the nucleus and represses its DNA-binding activity

To understand how Dvl modulates NF- $\kappa B$ signaling, we first asked whether Dvl would affect the TNF- $\alpha-$
A
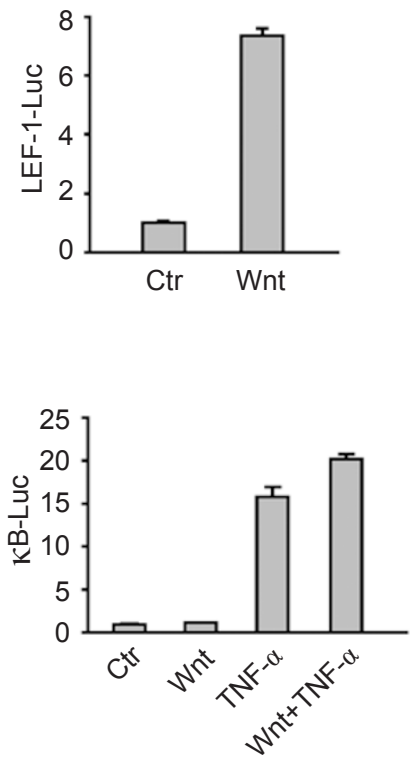

C

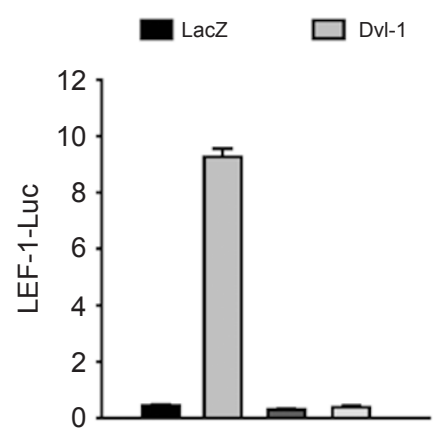

B
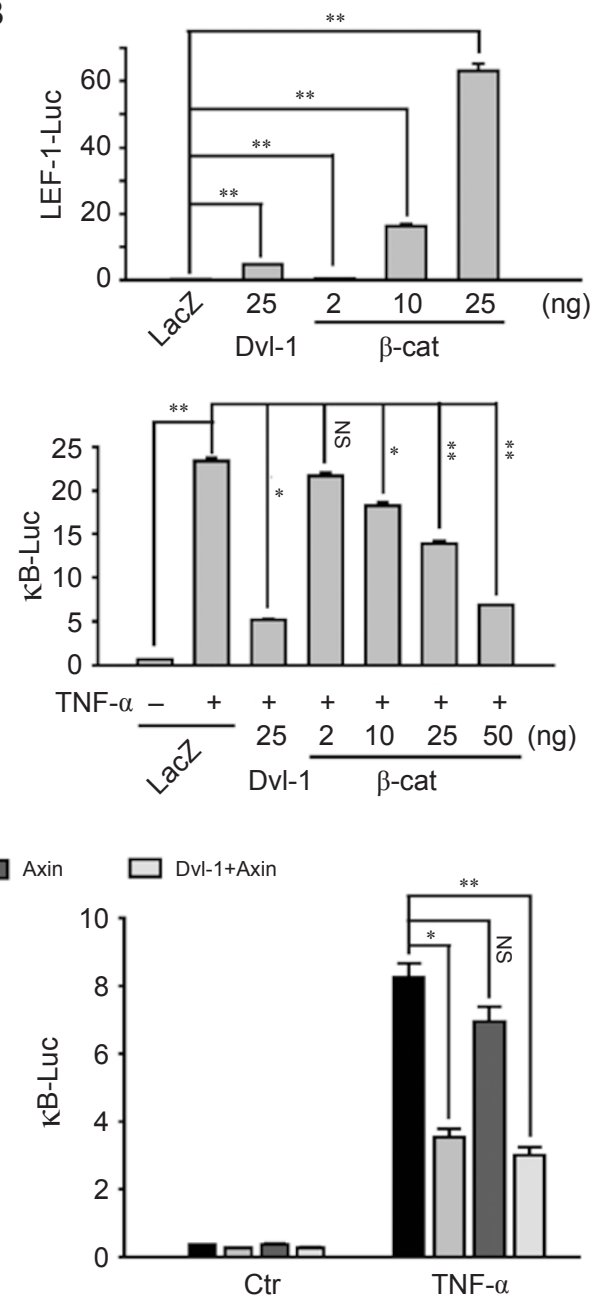

Figure $3 \mathrm{Dvl}$-mediated inhibition of NF-kB is independent of Wnt signaling or its downstream component $\beta$-catenin. (A) Effect of Wnt3a on TNF- $\alpha$-induced NF-kB activity. Cells were transfected with LEF-1-Luc (top) or kB-Luc (bottom) reporter gene overnight and either untreated or treated with Wnt-3a and TNF- $\alpha$ separately or together. (B) Effects of Dvl and different amounts of $\beta$-catenin on LEF-1-Luc or $\kappa B$-Luc reporter activity. Cells were transfected with LEF-1-Luc (top) or $\kappa B$-Luc (bottom) reporter gene plus $25 \mathrm{ng} \mathrm{Dvl-1}$ and different dose amounts of $\beta$-catenin overnight. (C) Axin inhibited the activation of LEF-1Luc reporter by Dvl, but did not relieve Dvl-mediated inhibition of NF-kB activity. Cells were transfected with LEF-1-Luc (left) or $\mathrm{kB}$-Luc (right) reporter gene and the indicated plasmids. After $24 \mathrm{~h}$, cells with $\mathrm{kB}$-Luc reporter gene were either untreated or treated with TNF- $\alpha$ for $8 \mathrm{~h}$. Data are shown as means \pm SD. $* P<0.05 ; * * P<0.01$; NS, no statistical significance. 


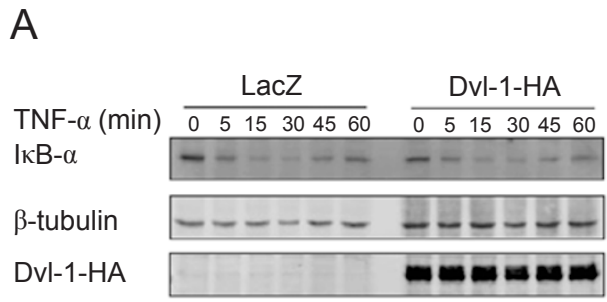

B Dvl-1-HA -+--+

Flag-|KB- $\alpha--+-\cdots+$

TNF- $\alpha \quad--+++$

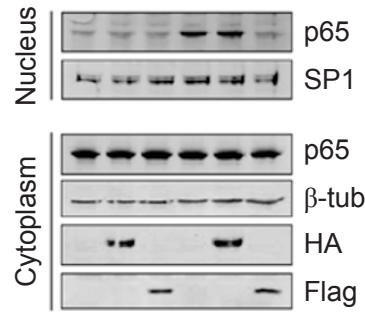

C

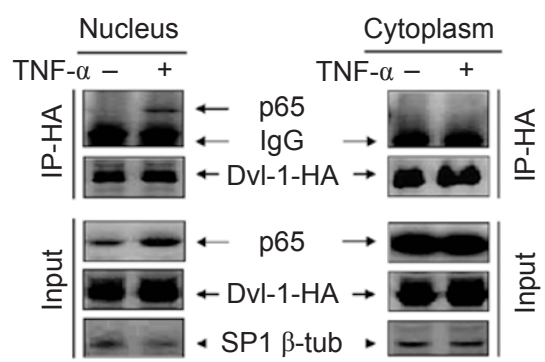

$D$

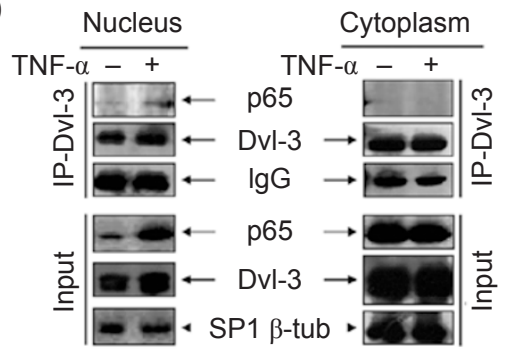

E

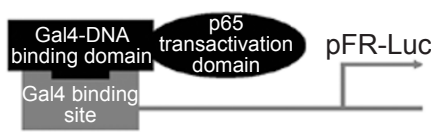

F
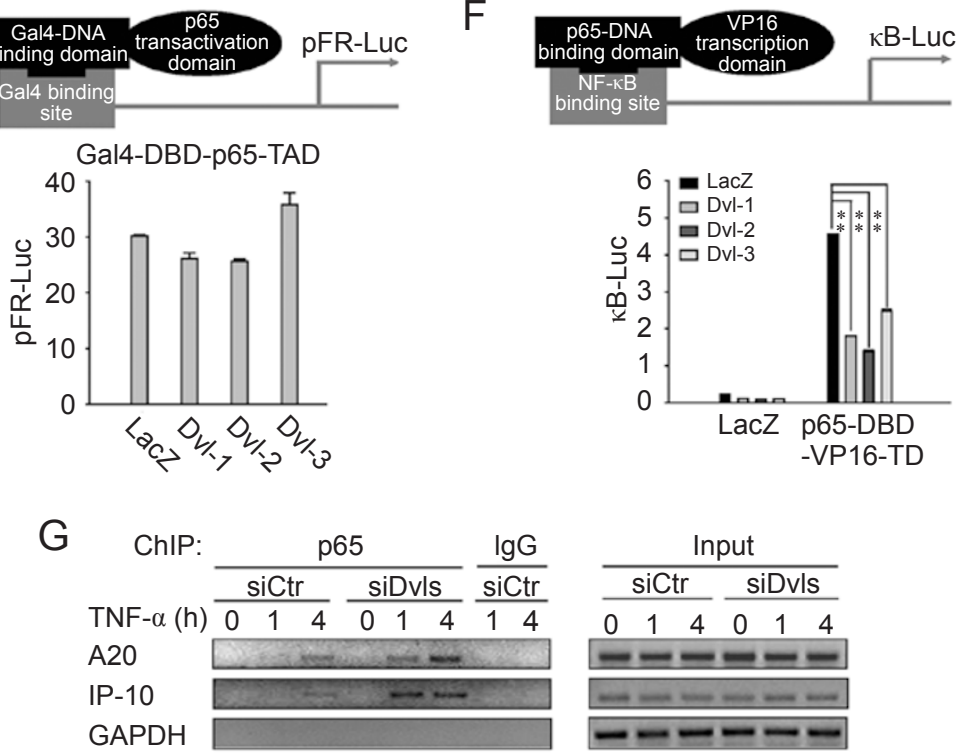

Figure $4 \mathrm{Dvl}$ interacts with $\mathrm{p} 65$ in the nucleus and represses its DNA-binding activity. (A) Dvl did not influence TNF- $\alpha$-induced $\mid \kappa B-\alpha$ degradation. Cells were transfected with DVl-1 expression plasmid and treated with TNF- $\alpha$ for the indicated times. Western blotting was performed on the cell extracts to check the degradation of IкB- $\alpha$. (B) Dvl did not affect TNF- $\alpha$-induced nuclear translocation of $p 65$. Cells were transfected with Dvl-1 or $I_{\kappa} B-\alpha$ as a positive control and either untreated or treated with TNF- $\alpha$ for $30 \mathrm{~min}$. Cytoplasmic and nuclear fractions were prepared and immunoblotted with the indicated antibodies, respectively. (C) Over-expressed Dvl interacted with endogenous p65 in the nucleus upon TNF- $\alpha$ stimulation. Cells were transfected with Dvl-1-HA and either untreated or treated with TNF- $\alpha$ for $30 \mathrm{~min}$. Cytoplasmic and nuclear fractions were prepared, immunoprecipitated with anti-HA antibody and subjected to western blotting analysis. (D) Nuclear p65 could be co-immunoprecipitated by anti-Dvl-3 antibody upon TNF- $\alpha$ stimulation. (E) Dvl did not induce any considerable change on Gal4-BDp65-TAD-mediated activation of pFR reporter gene. Cells were transfected with pFR reporter gene, Gal4-BD-p65-TAD fusion protein plus Dvl1-3, respectively. After $24 \mathrm{~h}$, cells were lysed and luciferase activities were determined. (F) Dvl repressed the activation of $\kappa B-L u c$ reporter gene by p65-DBD-VP16-TD. Cells were transfected with $\kappa B-L u c$ reporter gene and the indicated plasmids for $24 \mathrm{~h}$. $* * P<0.01$. (G) Binding of p65 to the endogenous A20 and IP-10 promoters upon TNF- $\alpha$ stimulation was enhanced by siRNA against Dvl. Cells were transfected with Dvl siRNA or control RNA and treated with TNF- $\alpha$ for the indicated times. The ChIP assays were performed in terms of A20, IP-10 or GAPDH promoters using anti-p65 antibody or IgG as a negative control. 
A

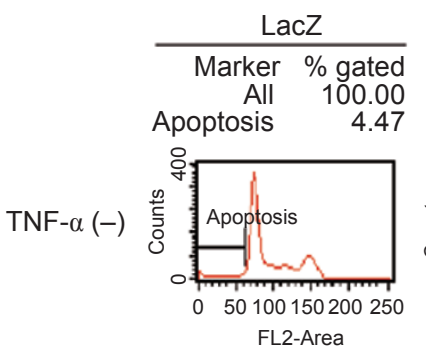

FL2-Area

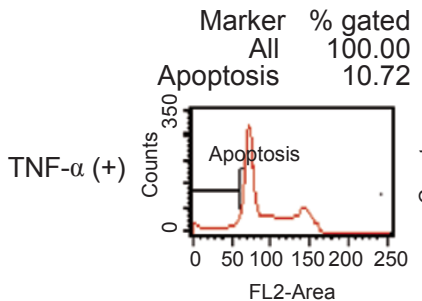

\begin{tabular}{rr}
\multicolumn{2}{c}{ Dvl-1 } \\
\hline Marker & $\%$ gated \\
All & 100.00 \\
Apoptosis & 6.09
\end{tabular}

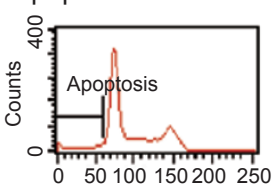

FL2-Area
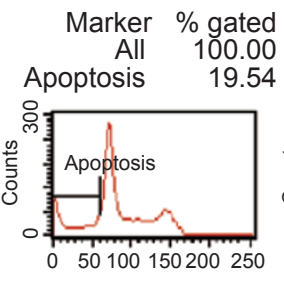

FL2-Area
Dvl-1-C2
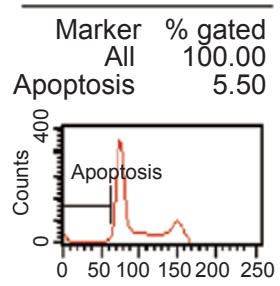

FL2-Area

Marker \% gated
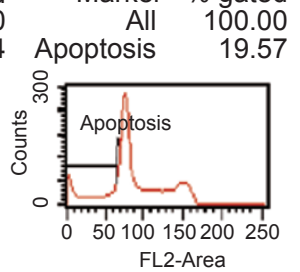

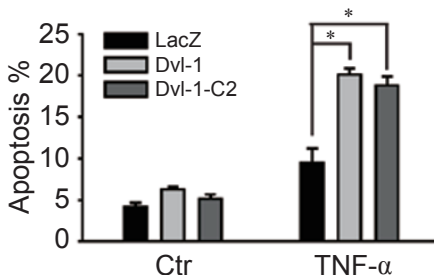

B
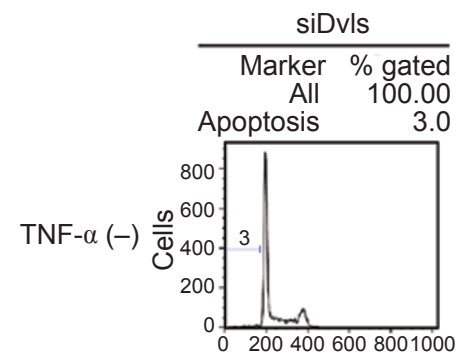

Marker \% gated
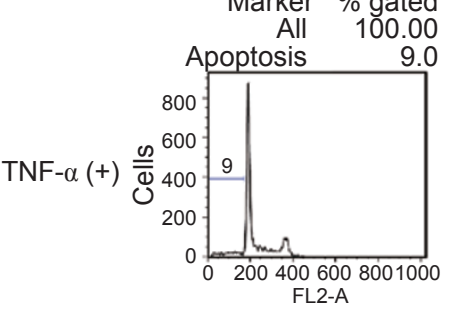

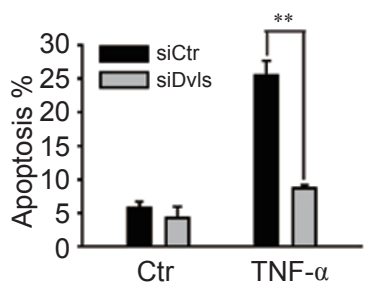

Figure 5 Dvl-1 and Dvl-1-C2 fragment sensitized cells to TNF- $\alpha$-induced apoptosis. (A) Over-expression of Dvl-1 or Dvl-1-C2 enhanced TNF- $\alpha$-induced apoptosis of 293 cells. Cells were transfected with Dvl-1 or Dvl-1-C2 expression plasmid. After $24 \mathrm{~h}$, cells were either untreated or treated with $50 \mathrm{ng} / \mathrm{ml} \mathrm{TNF- \alpha}$ for an additional $24 \mathrm{~h}$ and then analyzed by FACS assay to monitor apoptosis. The percentages indicate the fractions of positive PI cells in total cells. Data represent means $\pm \mathrm{SD} .{ }^{*} P<0.05$. (B) Knock-down of Dvl repressed TNF- $\alpha$-induced apoptosis. Cells were transfected with Dvl siRNA or control RNA. After $36 \mathrm{~h}$, cells were prepared as in (A). ${ }^{* *} P<0.01$.

induced IкB- $\alpha$ degradation and subsequent nuclear translocation of NF- $\kappa B$ p65. 293T cells transfected with Dvl were treated with $10 \mathrm{ng} / \mathrm{ml} \mathrm{TNF-} \alpha$ and western blotting was performed on the cell extracts to check the degradation of IкB- $\alpha$ (Figure 4A), or on the nuclear and cytoplasmic extracts to examine the nuclear translocation of $\mathrm{p} 65$ (Figure 4B). The results showed that neither endogenous I $\mathrm{KB}-\alpha$ protein degradation nor $\mathrm{p} 65$ nuclear translocation induced by TNF- $\alpha$ stimulation was affected upon by Dvl over-expression (Figure 4A and 4B). In Figure 4B, IкB- $\alpha$ was also transfected as a positive control and completely blocked p65 nuclear translocation as expected.

The fact that Dvl interacts with p65, but does not affect its nuclear translocation, together with the above finding that Dvl significantly blocks p65-mediated transcriptional activation (Figure 2A, left), strongly suggests that Dvl probably regulates NF- $\mathrm{KB}$ at the level of p65 in the nucleus. Indeed, we found that both over-expressed and endogenous Dvl interacted with p65 only in the nucleus but not in the cytoplasm (Figure 4C and 4D). 
To identify the region of p65 responding to Dvl inhibition, we tested two fusion proteins in the corresponding reporter gene system: one composed of the Gal4 DNAbinding domain and a C-terminal region of p65 (amino acids 285-551) that includes the TAD (designated as Gal4-DBD-p65-TAD), and the other a fusion of an Nterminal region of $\mathrm{p} 65$ (amino acids 1-285) that includes the DNA-binding domain with the VP16 transcription activation domain (designated as p65-DBD-VP16TD). Expression of Gal4-DBD-p65-TAD fusion protein resulted in a high level of expression of the pFR-Luc reporter gene. Upon the addition of Dvl1-3, the activity of Gal4-DBD-p65-TAD was almost unaffected (Figure $4 \mathrm{E})$. Then we used p65-DBD-VP16-TD in the NF- $\kappa B$ reporter assay and found that this fusion protein potently activated the $\kappa \mathrm{B}$-Luc reporter gene, but the activation was repressed strongly by co-transfection of Dvls (Figure $4 \mathrm{~F}$ ), suggesting that the inhibition of $\mathrm{p} 65$ by Dvl was mediated through the N-terminal region of $\mathrm{p} 65$.

Since the region encompassing residues 1-285 in p65 contains the DNA-binding sequence, it is possible that Dvl inhibits NF- $\kappa \mathrm{B}$-mediated transcription by blocking the DNA-binding activity of $\mathrm{p} 65$. To explore this hypothesis, we transfected Dvl siRNA into 293T cells and performed chromatin immunoprecipitation (ChIP) assays to examine the binding of p65 to the promoters of endogenous NF- $\kappa \mathrm{B}$ target genes. It turned out that the binding of $\mathrm{p} 65$ to the endogenous A20 and IP-10 promoters upon TNF- $\alpha$ stimulation was significantly enhanced after knock-down of Dvl (Figure 4G), confirming that Dvl inhibits the activity of NF- $\mathrm{KB}$ by interfering with the recruitment of $\mathrm{p} 65$ to the promoters of NF- $\mathrm{kB}$-regulated genes.

Dvl sensitizes 293 cells to TNF- $\alpha$-induced apoptosis possibly via relieving anti-apoptotic effect of $N F-\kappa B$

It was reported previously that over-expression of Dvl could cause cell death due to the induction of apoptosis, and one possible mechanism was provided: Dvl promoted apoptosis by activating JNK, which is capable of activating apoptosis in response to numerous cellular stresses [22, 26, 27]. In our work, we found that Dvl negatively regulates NF- $\mathrm{kB}$, a signaling pathway known to act as a suppressor of apoptosis in most cells by inducing anti-apoptotic gene expression, which prompted us to raise another potential mechanism: Dvl might inhibit $\mathrm{NF}-\kappa \mathrm{B}$ and relieve the anti-apoptotic effects of NF- $\kappa \mathrm{B}$, thus play a role in promoting apoptosis. To test this hypothesis, the Dvl-1-C2 fragment was used to exclude the effect of JNK, as a previous report has documented that such a fragment was unable to activate JNK [22]. More importantly, Dvl-1-C2 represents the region responsible for interaction with p65 and was found to repress both TNF- $\alpha$ - and $\mathrm{p} 65$-induced NF- $\kappa \mathrm{B}$ activation as full-length Dvl does (data not shown). Using propidium iodide (PI) staining of dead cells and FACS analysis, we found that over-expression of Dvl-1-C2 as well as Dvl sensitized cells to TNF- $\alpha$-induced apoptosis (Figure 5A). Consistently, we used siRNA to knock down Dvl expression, and found that TNF- $\alpha$-induced apoptosis of 293 cells was drastically inhibited (Figure 5B). These findings support the idea that Dvl could promote TNF $\alpha$-induced apoptosis by inhibiting NF- $\mathrm{KB}$ activation.

\section{Discussion}

Extensive studies have been performed to address how Dvl works in both canonical Wnt and non-canonical Wnt signaling pathways. The fact that there are three Dvls in mammals and that they are found to interact with a great variety of proteins suggests that Dvl may have functions in addition to Wnt signaling. In this paper, we examined the role of Dvl in the regulation of NF- $\kappa \mathrm{B}$ signaling. NF$\kappa \mathrm{B}$ plays an important role in a wide spectrum of cellular responses and needs to be regulated properly at multilevels; inappropriate regulation of $\mathrm{NF}-\mathrm{kB}$ is involved in a number of human diseases. Besides the well-characterized feedback pathway whereby newly synthesized IкB- $\alpha$ serves to shut off the signal [28], recent studies have gradually revealed a series of molecules, including A20 $[29,30]$, CYLD [31, 32], Twist [33], $\beta$-arrestins [34, 35] and PIAS [36, 37], all of which are capable of regulating $\mathrm{NF}-\mathrm{\kappa B}$ activity negatively. Here our work revealed that Dvl protein also serves as a negative regulator of NF- $\mathrm{kB}$ signaling. First, we provided evidence that Dvl interacted with the p65 subunit of NF- $\mathrm{\kappa B}$ by co-IP experiment (Figure $1 \mathrm{~B})$. In vitro binding experiment using purified recombinant proteins of Dvl C-terminal fragment and p65 $\mathrm{N}$-terminal fragment confirmed their direct interaction (Figure 1D). Further, we found that over-expression of Dvl led to inhibition of TNF- $\alpha$-mediated NF- $\mathrm{kB}$ activity, while knock-down of endogenous Dvl by RNAi resulted in up-regulation of TNF- $\alpha$-induced NF- $\kappa$ B activity (Figure 2A). Importantly, the inhibition of NF- $\kappa$ B by Dvl was not dependent on Wnt signaling or its downstream component $\beta$-catenin (Figure 3). Taken together, these results revealed a novel function of Dvl in inhibiting the NF- $\mathrm{KB}$ signaling pathway, aside from its role in Wnt signaling.

It is generally agreed that Dvl mainly locates in the cytoplasm to relay signals to downstream signaling components. Recent work has shown that Dvl also exists in the nucleus and its nuclear localization is required for the signal transduction [6]. Moreover, work from our lab has revealed that nuclear Dvl could form a quaternary com- 
plex with c-Jun, $\beta$-catenin and TCF and plays an important role in gene transcription [7]. In this work, we found that over-expressed Dvl did not affect I $\mathrm{I} B-\alpha$ degradation and p65 nuclear translocation, but interacted with endogenous p65 in the nucleus upon TNF- $\alpha$ stimulation (Figure $4 \mathrm{~A}-4 \mathrm{C}$ ). Using cell fractionation, we also detected a small portion of endogenous Dvl existing in the nucleus and only this part of Dvl could interact with p65 (Figure 4D). Here a ligand-dependent interaction between nuclear Dvl and p65 was observed, but how TNF- $\alpha$ regulates Dvl-p65 binding is not clear. In other words, the different activity of nuclear and cytosolic Dvl with respect to p65 binding is not fully understood yet. One possible explanation is that cytosolic Dvl or p65 may be labeled by some kind of modification or may associate with other proteins that render them unable to bind to each other, while in the nucleus, this kind of inhibition is removed and the interaction between these two proteins occurs.

ChIP assays showed that the binding of p65 to the promoters of NF- $\mathrm{KB}$-regulated genes was significantly enhanced after knock-down of Dvl, suggesting that Dvl inhibits the activity of NF- $\mathrm{KB}$ probably by blocking the DNA-binding activity of p65 (Figure 4G). Consistently, using quantitative real-time PCR, we showed that the expression of several NF- $\kappa$ B-regulated genes (I $\mathrm{KB}-\alpha, \mathrm{A} 20$, IP-10 and GADD45 $\beta$ ) was elevated when expression of Dvl was suppressed or attenuated when Dvl was overexpressed (Figure 2B and 2C). Among these target genes, A20 and GADD45 $\beta$ were known to act as anti-apoptotic genes to protect cells from apoptosis [38, 39], which prompted us to propose the possibility that Dvl could relieve NF-kB's anti-apoptotic effects and therefore promote apoptosis. Actually, Dvl's pro-apoptosis role has been described before [26], but the mechanism was not clarified and seemed complicated. Since Dvl could activate JNK, which is capable of activating apoptosis, Dvlpromoted cell death via JNK activation could be considered as one possible explanation. In our system, a Dvl fragment (Dvl-1-C2) that is unable to activate JNK still retains the ability to regulate $\mathrm{NF}-\mathrm{\kappa B}$ activity, excluding the effect of JNK and suggesting that Dvl could promote $\mathrm{TNF} \alpha$-induced apoptosis by inhibiting NF- $\kappa \mathrm{B}$ activation (Figure 5A and 5B).

Collectively, our study reveals that Dvl is a novel negative regulator of $\mathrm{NF}-\kappa \mathrm{B}$ signaling. This function does not seem to be dependent on Wnt or its downstream component $\beta$-catenin. Moreover, Dvl interacts with $\mathrm{p} 65$ in the nucleus to suppress the DNA-binding activity of p65. As a result, the expression of a series of NF- $\kappa B$ target genes, including several anti-apoptotic genes, is repressed and cells becomes more sensitized to apoptosis. Apoptosis is essential for organisms to maintain ho- meostasis and develop normally. Over-activated NF-кB causes cells to escape from apoptosis and is associated with a number of cancers. Due to Dvl's inhibition of NF$\kappa \mathrm{B}$ and promotion of apoptosis, it is possible that Dvl may act as a supervisor to control the strength of NF- $\mathrm{kB}$ signaling and regulate the elimination of old cells, unnecessary cells, and unhealthy cells.

\section{Materials and Methods}

\section{Reagents and plasmids}

Anti-Dvl-2 antibody was purchased from Santa Cruz Biotechnology, Inc. The myeloma cell line secreting anti-Dvl-3 antibody was kindly provided by Daniel Sussman. siRNA duplexes were chemically synthesized by GenePharma and sequences targeting Dvl-2 and Dvl-1/3 have been described previously [7]. p65 and I $\mathrm{B}-\alpha$ antibodies were purchased from Santa Cruz Biotechnology, Inc. TNF- $\alpha$ was purchased from R\&D Systems. The Wnt-3a-containing conditioned medium was prepared as previously described [40].

Dvl-1/2/3, p65 and their deletion mutants were constructed by a PCR-based approach and subsequently cloned into mammalian or bacterial expression vectors as indicated. $\beta$-Catenin and Axin were amplified by PCR and cloned into pcDNA3 vectors (Invitrogen) with HA-tag at the N-terminus. Flag-IкB- $\alpha$, Gal4-DBD-p65-TAD, p65-DBD-VP16-TD and the reporter genes ( $\kappa$ B-Luc and pFR-Luc) were kindly provided by C Wang (SIBCB, Shanghai, China).

\section{Cell culture and DNA transfection}

HEK293 and HEK293T cells were obtained from ATCC (Manassas, VA) and cultured in Dulbecco's modified Eagle's medium supplemented with $10 \%$ fetal bovine serum. DNA was transfected into cells using Lipofectamine Plus and siRNA was transfected using Lipofectamine 2000 (Invitrogen) as instructed.

\section{Luciferase assay}

Cells were seeded in 24-well plates and transfected plasmids or siRNA combined with reporters as indicated. LacZ was used to keep the total amount of transfected DNA constant. After transfection, cells were treated with the indicated reagents or left untreated. Luciferase assays were performed as previously described [22].

\section{Co-IP assay}

Whole-cell lysates were prepared $24 \mathrm{~h}$ post-transient transfection in a lysis buffer containing $20 \mathrm{mM}$ Tris ( $\mathrm{pH} 8.0$ ), 138 $\mathrm{mM} \mathrm{NaCl}, 10 \%$ glycerol, $1 \%$ Nonidet P-40, $10 \mathrm{mM} \mathrm{NaF}, 2 \mathrm{mM}$ $\mathrm{NaVO}_{4}, 1 \mathrm{mM}$ pyrophosphoric acid and Complete ${ }^{\mathrm{TM}}$ protease inhibitors (Roche Applied Science). The mixture was incubated on ice for $10 \mathrm{~min}$ and centrifuged at 14000 r.p.m. for $10 \mathrm{~min}$. The supernatant was collected and mixed with Protein A/G plus-agarose (Santa Cruz) and various antibodies for $3 \mathrm{~h}$ at $4{ }^{\circ} \mathrm{C}$. Bound proteins were then eluted and subjected to western blotting analysis.

\section{Real-time RT-PCR}

Total cellular RNA was isolated with TRIzol (Invitrogen) as instructed. Reverse transcription of purified RNA was performed using SuperScript III (Invitrogen). The quantification of gene transcripts was analyzed by real-time PCR with SYBR green. 
Expression values were normalized to the level of $\beta$-actin mRNA. The primers used are listed as follows: I $\mathrm{B}-\alpha$, sense (CTG AAG GCT ACC AAC TAC AAT) and antisense (CAC CCA AGG ACA CCA AAA); A20, sense (GCG TTC AGG ACA CAG ACT TG) and antisense (GCA AAG CCC CGT TTC AAC AA); IP-10, sense (GAA AGC AGT TAG CAA GGA A) and antisense (GTA ACT GCA AAC TAA GAA CAA T); GADD45 $\beta$, sense (TCA CGC TCA TCC AGT CCT) and antisense (CGG CTT TCT TCG CAG TA); $\beta$-actin, sense (AAA GAC CTG TAC GCC AAC AC) and antisense (GTC ATA CTC CTG CTT GCT GAT).

\section{Cell fractionation}

Cells were scraped with a cell scraper into $1.5 \mathrm{ml}$ of PBS and collected by spinning at 3000 r.p.m. for $10 \mathrm{~min}$. The pellet cells were resuspended in buffer A (10 mM HEPES, pH 7.9, $1.5 \mathrm{mM}$ $\mathrm{MgCl}_{2}, 10 \mathrm{mM} \mathrm{KCl}, 0.5 \mathrm{mM}$ DTT and Complete ${ }^{\mathrm{TM}}$ protease inhibitors) and incubated on ice for $10 \mathrm{~min}$. Nonidet P-40 was added to a final concentration of $0.1 \%$ and the cells were vortexed for $10 \mathrm{~s}$ and then centrifuged at 4000 r.p.m. at $4{ }^{\circ} \mathrm{C}$ for $10 \mathrm{~min}$. The supernatant on top was collected as the cytosolic fraction. For nuclear extraction, the pellet was washed by buffer $\mathrm{A}$ once, then resuspended in buffer $\mathrm{C}$ (20 mM HEPES, pH 7.9, $1.5 \mathrm{mM} \mathrm{MgCl}, 420$ $\mathrm{mM} \mathrm{NaCl}, 0.2 \mathrm{mM}$ EDTA, 25\% glycerol and Complete ${ }^{\mathrm{TM}}$ protease inhibitors) and incubated on ice for $1 \mathrm{~h}$ with a vigorous agitation occasionally. Nuclear extracts (supernatants) were recovered after centrifugation at 14000 r.p.m. for $10 \mathrm{~min}$.

\section{ChIP assay}

HEK293T cells were treated with $10 \mathrm{ng} / \mathrm{ml} \mathrm{TNF-} \alpha$ for the indicated times prior to formaldehyde cross-linking. The ChIP assay was performed according to the ChIP Procotol (Upstate). The following promoter-specific primers were used: human IP-10, sense (ACA GTT CAT GTT TTG GAA AGT) and antisense (TCC CTA ATT CTG ATT GGA TAA). primers used to amplify the human A20 and GAPDH promoters were synthesized as described previously [41].

\section{Apoptosis assay}

HEK293 cells were transfected with the indicated plasmids or siRNA. At $24 \mathrm{~h}$ (when transfected with plasmids) or $36 \mathrm{~h}$ (when transfected with siRNA) after transfection, cells were treated with $50 \mathrm{ng} / \mathrm{ml} \mathrm{TNF}-\alpha$ for another $24 \mathrm{~h}$. Then the cells were collected, fixed by ethanol and labeled by $30 \mathrm{~g} / \mathrm{ml}$ PI. The flow cytometer used was a FACSCalibur (BD Biosciences).

\section{Acknowledgments}

This work was supported by the Ministry of Science and Technology of China (2010CB912100 and 2007CB914500), the National Natural Science Foundation of China (30821065, 30930052 and 90813024), and the Science and Technology Commission of Shanghai Municipality.

\section{References}

1 Peifer M, Polakis P. Wnt signaling in oncogenesis and embryogenesis-a look outside the nucleus. Science 2000; 287:1606-1609.

2 Goldstein B, Takeshita H, Mizumoto K, Sawa H. Wnt signals can function as positional cues in establishing cell polarity. Dev Cell 2006; 10:391-396.

3 Moon RT, Brown JD, Torres M. WNTs modulate cell fate and behavior during vertebrate development. Trends Genet 1997; 13:157-162.

4 Fuerer C, Nusse R, Ten Berge D. Wnt signalling in development and disease. EMBO Rep 2008; 9:134-138.

5 Van Amerongen R, Nusse R. Towards an integrated view of Wnt signaling in development. Development 2009; 136:32053214.

6 Itoh K, Brott BK, Bae GU, Ratcliffe MJ, Sokol SY. Nuclear localization is required for Dishevelled function in Wnt/ $\beta$-catenin signaling. J Biol 2005; 4:3.

7 Gan XQ, Wang JY, Xi Y, Wu ZL, Li YP, Li L. Nuclear Dvl, cJun, $\beta$-catenin, and TCF form a complex leading to stabilization of $\beta$-catenin-TCF interaction. J Cell Biol 2008; 180:10871100 .

8 Boutros M, Mlodzik M. Dishevelled: at the crossroads of divergent intracellular signaling pathways. Mech Dev 1999; 831:27-37.

9 Veeman MT, Axelrod JD, Moon RT. A second canon. Functions and mechanisms of $\beta$-catenin-independent Wnt signaling. Dev Cell 2003; 5:367-377.

10 Wharton KA Jr. Runnin' with the Dvl: proteins that associate with Dsh/Dvl and their significance to Wnt signal transduction. Dev Biol 2003; 253:1-17.

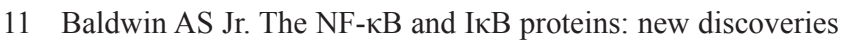
and insights. Annu Rev Immunol 1996; 14:649-683.

12 Ghosh S, May MJ, Kopp EB. NF-кB and Rel proteins: evolutionarily conserved mediators of immune responses. Annu Rev Immunol 1998; 16:225-260.

13 Baeuerle PA, Baichwal VR. NF- $\kappa \mathrm{B}$ as a frequent target for immunosuppressive and anti-inflammatory molecules. $A d v$ Immunol 1997; 65:111-137.

14 Mercurio F, Manning AM. NF- $\kappa \mathrm{B}$ as a primary regulator of the stress response. Oncogene 1999; 18:6163-6171.

15 Hayden MS, Ghosh S. Signaling to NF-кB. Genes Dev 2004; 18:2195-2224.

16 Barnes PJ, Karin M. Nuclear factor- $\kappa$ B: a pivotal transcription factor in chronic inflammatory diseases. N Engl J Med 1997; 336:1066-1071.

17 Gilmore TD, Koedood M, Piffat KA, White DW. Rel/NF- $\kappa$ B/ IкB proteins and cancer. Oncogene 1996; 13:1367-1378.

18 Rayet B, Gelinas C. Aberrant rel/nfkb genes and activity in human cancer. Oncogene 1999; 18:6938-6947.

19 Sussman DJ, Klingensmith J, Salinas P, Adams PS, Nusse R, Perrimon N. Isolation and characterization of a mouse homolog of the Drosophila segment polarity gene dishevelled. Dev Biol 1994; 166:73-86.

20 Klingensmith J, Yang Y, Axelrod JD, Beier DR, Perrimon N, Sussman DJ. Conservation of dishevelled structure and function between flies and mice: isolation and characterization of Dv12. Mech Dev 1996; 58:15-26.

21 Tsang M, Lijam N, Yang Y, Beier DR, Wynshaw-Boris A, Sussman DJ. Isolation and characterization of mouse dishevelled-3. Dev Dyn 1996; 207:253-262.

22 Li L, Yuan H, Xie W, et al. Dishevelled proteins lead to two signaling pathways. Regulation of LEF-1 and c-Jun N-terminal kinase in mammalian cells. J Biol Chem 1999; 274:129- 
134.

23 Wallingford JB, Habas R. The developmental biology of Dishevelled: an enigmatic protein governing cell fate and cell polarity. Development 2005; 132:4421-4436.

24 Masui O, Ueda Y, Tsumura A, Koyanagi M, Hijikata M, Shimotohno K. RelA suppresses the Wnt/ $\beta$-catenin pathway without exerting trans-acting transcriptional ability. Int $\mathrm{J} \mathrm{Mol}$ Med 2002; 9:489-493.

25 Deng J, Miller SA, Wang HY, et al. $\beta$-catenin interacts with and inhibits NF- $\mathrm{kB}$ in human colon and breast cancer. Cancer Cell 2002; 2:323-334.

26 Strovel ET, Sussman DJ. Transient overexpression of murine dishevelled genes results in apoptotic cell death. Exp Cell Res 1999; 253:637-648.

27 Minden A, Karin M. Regulation and function of the JNK subgroup of MAP kinases. Biochim Biophys Acta 1997; 1332:85104.

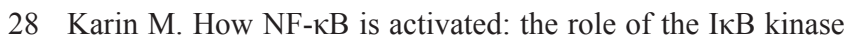
(IKK) complex. Oncogene 1999; 18:6867-6874.

29 Jaattela M, Mouritzen H, Elling F, Bastholm L. A20 zinc finger protein inhibits TNF and IL-1 signaling. J Immunol 1996; 156:1166-1173.

30 Song HY, Rothe M, Goeddel DV. The tumor necrosis factorinducible zinc finger protein A20 interacts with TRAF1/ TRAF2 and inhibits NF-kB activation. Proc Natl Acad Sci USA 1996; 93:6721-6725.

31 Kovalenko A, Chable-Bessia C, Cantarella G, Israël A, Wallach D, Courtois G. The tumour suppressor CYLD negatively regulates NF- $\mathrm{\kappa B}$ signalling by deubiquitination. Nature 2003; 424:801-805.

32 Trompouki E, Hatzivassiliou E, Tsichritzis T, Farmer H, Ashworth A, Mosialos G. CYLD is a deubiquitinating enzyme that negatively regulates NF- $\mathrm{kB}$ activation by TNFR family members. Nature 2003; 424:793-796.

33 Sosić D, Richardson JA, Yu K, Ornitz DM, Olson EN. Twist regulates cytokine gene expression through a negative feedback loop that represses NF-kB activity. Cell 2003; 112:169180.

$34 \mathrm{Gao} \mathrm{H}$, Sun $\mathrm{Y}, \mathrm{Wu} \mathrm{Y}$, et al. Identification of $\beta$-arrestin2 as a G protein-coupled receptor-stimulated regulator of NF-kB pathways. Mol Cell 2004; 14:303-317.

35 Witherow DS, Garrison TR, Miller WE, Lefkowitz RJ. $\beta$-Arrestin inhibits NF- $\mathrm{KB}$ activity by means of its interac-

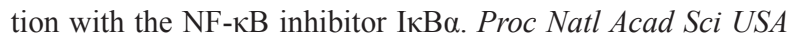
2004; 101:8603-8607.

36 Liu B, Yang R, Wong KA, et al. Negative regulation of NFКB signaling by PIAS1. Mol Cell Biol 2005; 25:1113-1123.

37 Liu B, Yang Y, Chernishof V, et al. Proinflammatory stimuli induce IKK $\alpha$-mediated phosphorylation of PIAS1 to restrict inflammation and immunity. Cell 2007; 129:903-914.

38 Malewicz M, Zeller N, Yilmaz ZB, Weih F. NF-kB controls the balance between Fas and tumor necrosis factor cell death pathways during $\mathrm{T}$ cell receptor-induced apoptosis via the expression of its target gene A20. J Biol Chem 2003; 278:3282532833.

39 Zazzeroni F, Papa S, Algeciras-Schimnich A, et al. Gadd45 $\beta$ mediates the protective effects of CD40 costimulation against Fas-induced apoptosis. Blood 2003; 102:3270-3279.

40 Mao J, Wang J, Liu B, et al. Low-density lipoprotein receptor-related protein- 5 binds to Axin and regulates the canonical Wnt signaling pathway. Mol Cell 2001; 7:801-809.

41 Sun S, Tang Y, Lou X, et al. UXT is a novel and essential cofactor in the NF-kB transcriptional enhanceosome. $J$ Cell Biol 2007; 178:231-244. 